\title{
Non-invasive prediction of recurrence in bladder cancer by detecting somatic TERT promoter mutations in urine
}

\author{
Françoise Descotes ${ }^{\star}, 1$, Norelyakin Kara ${ }^{2}$, Myriam Decaussin-Petrucci ${ }^{3,4}$, Eric Piaton ${ }^{5}$, Florence Geiguer ${ }^{1}$, \\ Claire Rodriguez-Lafrasse ${ }^{1}$, Jean E Terrier ${ }^{2}$, Jonathan Lopez ${ }^{1,4}$ and Alain Ruffion ${ }^{2,4}$ \\ ${ }^{1}$ Hospices Civils de Lyon, Service de Biochimie Biologie Moléculaire, Centre Hospitalier Lyon Sud, Pierre Bénite Cedex 69495, \\ France; ${ }^{2}$ Hospices Civils de Lyon, Service d'Urologie, Centre Hospitalier Lyon Sud, Pierre Bénite Cedex 69495, France; ${ }^{3}$ Hospices \\ Civils de Lyon, Service d'Anatomie et Cytologie Pathologiques, Centre Hospitalier Lyon Sud, Pierre Bénite Cedex 69495, France; \\ ${ }^{4}$ Université Lyon 1, Centre de Recherche en Cancérologie de Lyon - INSERM 1052 CNRS 5286, Centre Léon Bérard, LYON cedex \\ 08 69373, France and ${ }^{5}$ Hospices Civils de Lyon, Centre de Pathologie Est, Hôpital Femme-Mère-Enfant, Boulevard Pinel, Bron \\ 69677, France
}

Background: Urothelial bladder cancer (UBC) is characterised by a high risk of recurrence. Patient monitoring is currently based on iterative cystoscopy and on urine cytology with low sensitivity in non-muscle-invasive bladder cancer (NMIBC). Telomerase reverse transcriptase (TERT) is frequently reactivated in UBC by promoter mutations.

Methods: We studied whether detection of TERT mutation in urine could be a predictor of UBC recurrence and compared this to cytology/cystoscopy for patient follow-up. A total of 348 patients treated by transurethral bladder resection for UBC were included together with 167 control patients.

Results: Overall sensitivity was $80.5 \%$ and specificity $89.8 \%$, and was not greatly impacted by inflammation or infection. TERT remaining positive after initial surgery was associated with residual carcinoma in situ. TERT in urine was a reliable and dynamic predictor of recurrence in NMIBC $(P<0.0001)$. In univariate analysis, TERT positive-status after initial surgery increased risk of recurrence by 5.34-fold $(P=0.0004)$. TERT positive-status was still associated with recurrence in the subset of patients with negative cystoscopy $(P=0.034)$.

Conclusions: TERT mutations in urine might be helpful for early detection of recurrence in UBC, especially in NMIBC.

Diagnosis and treatment of patients presenting an urothelial bladder cancer (UBC) is a major challenge for clinicians. Prognosis for UBC is tightly correlated to stage and grade; the two main entities depend on infiltration of the muscle layer and are nonmuscle-invasive bladder cancer (NMIBC) and muscle-invasive bladder cancer (MIBC). The association of urine cytology and cystoscopy is the current gold standard to detect recurrence and monitor UBC. The main advantage of urine cytology is that it is non-invasive, cheap, and easy to perform. Its high specificity
(90-98\%) makes cytology an interesting test to monitor high-grade tumours, with sensitivity up to $90 \%$ in pTis (Grossman et al, 2007; Geavlete et al, 2012). Unfortunately, overall sensitivity to detect tumour cells ranges from 22 to $62 \%$ (Koss et al, 1985; Piaton et al, 2004; Bassi et al, 2005) making it unsuitable for low-grade lesions (Fontaniere et al, 2001). Although the current gold standard is cystoscopy and cytology, it is subjective and may vary with the experience of the observers (Miremami and Kyprianou, 2014). This is particularly a problem in some conditions (elderly patients or

*Correspondence: Dr F Descotes; E-mail: francoise.descotes@chu-lyon.fr

Received 13 March 2017; revised 31 May 2017; accepted 8 June 2017; published online 6 July 2017

(C) 2017 Cancer Research UK. All rights reserved 0007 - 0920/17 
in PBS and frozen at $-80^{\circ} \mathrm{C}$ until use. DNA was extracted from urine sediment using Circulating Nucleic Acid Kit QIAamp according to the manufacturer's recommendations (Qiagen, Hilden, Germany). Mutations of TERT promoter were analysed by nested PCR and Sanger sequencing. The first PCR (forward $5^{\prime}-\mathrm{C}$ ACCCGTCCTGCCCCTTCACCTT- $3^{\prime}$ and reverse $5^{\prime}$-GGCTT CCCACGTGCGCAGCAGGA-3') amplifies a 275-bp fragment that is used as matrix for a second PCR (forward $5^{\prime}$-CCC CTTCACCTTCCAGCTC- $3^{\prime}$ and reverse $5^{\prime}$-GCCGCGGAAAGG AAGG-3') amplifying a fragment of $118 \mathrm{bp}$ carrying the points -124 mutation $(\mathrm{C} 228 \mathrm{~T})$ and -146 (C250T). PCR products were then sequenced according to the Sanger method.

Statistical analysis. Quantitative variables were compared between groups using Mann-Whitney test and categorical variables using the $\chi^{2}$-test or Fisher's exact test. Survival analyses were performed in the population of patients with positive TERT mutation at the time of TUBR. Analysis was restricted to superficial UBC stages, excluding pTis stage. Absence of recurrence was defined as no event with a minimum follow-up of 6 months. Median follow-up was 11.3 months (range: (1.3-117)). The Kaplan-Meier method was used to estimate recurrence-free survival (RFS), and curves were compared using the Log-rank test. Univariate and multivariate analysis were performed using Cox proportional hazard model with 95\% confidence intervals (CI). All tests were set at the significance level of $P<0.05$. Statistical analyses were performed using the IBM SPSS Statistics software (release 19).

\section{RESULTS}

Recurrent somatic TERT promoter mutations in urine from UBC patients. Urine from 348 patients was collected at the time of initial TURB and tested for TERT promoter mutations. This cohort included 275 NMIBC (pTa or pT1), 61 MIBC (>pT1), and 12 carcinoma in situ (CIS). The overall TERT mutation rate was $80.5 \%$ (280 out of 348 ). TERT positivity in urine was stageindependent; sensitivity was 79.4 in $\mathrm{pTa}$ and $77.6 \%$ in pT1 NMIBC, increasing to 85.2 in MIBC ( $>$ pT1) and $91.7 \%$ in pTis. There was a higher frequency of TERT mutations among highgrade tumours than among low-grade ones $(P=0.0193)$; sensitivity in low-grade lesions was $74.3 \%$ (Table 1). Among TERT promoter hotspot mutations, C228T was the most prevalent (235 out of 280, $83.9 \%$ ), followed by C250T ( 35 out of 280 ). There were also rarer substitutions in some patients (C228A and CC242TT), and in two patients concomitant mutations of both C228T and C250T.

Comparison of TERT mutations to cytology for the detection of UBC. TERT positivity was not significantly correlated with urine cytology classification (Table 1). Regardless of tumour stage, sensitivity of TERT mutations (280 out of $348,80.5 \%)$ was significantly higher than urine cytology (117 out of $348,33.6 \%$ ) $\left(\chi^{2}\right.$-test $\left.P<0.0001\right)$. The overall sensitivity to detect UBC was for stratification of NMIBC in three groups (low-grade pTa, highgrade $\mathrm{pTa} / \mathrm{pTis}$ and $\mathrm{pT} 1$ ) showed a sensitivity of cytology of $5.5 \%$, $43.3 \%$, and $50 \%$, respectively whereas sensitivity of TERT remained high whatever the group $(74.3 \%, 92.5 \%$, and $77.6 \%$, respectively; Figure 1). Of note, sensitivity of TERT in MIBC ( $>$ pT1) was not significantly different from cytology $(P=0.0515)$.

Specificity of TERT mutation detection in urine. To assess the specificity of this test we included 167 'non-UBC' patients including 125 with benign bladder lesion or healthy individuals, and 42 with other cancers (Table 2). Specificity was 92.0\% (115 out of 125) in those with benign bladder lesion or healthy individuals, and $83.3 \%$ in cancer patients (35 out of 42 ). Among those with infectious or inflammatory urines (neurogenic bladder), only one

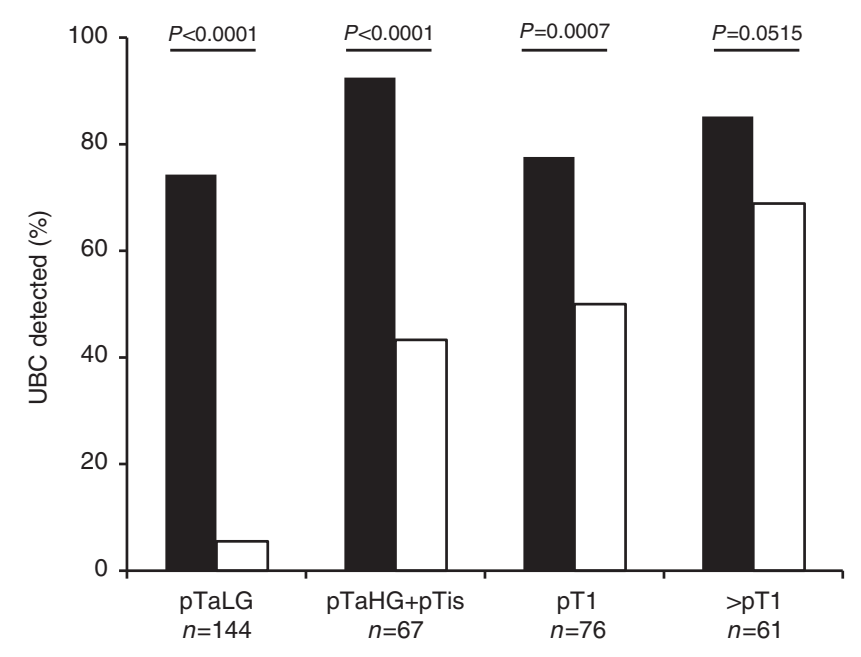

Figure 1. Distribution of somatic TERT promoter mutation and positive urine cytology among tumour stage in the 348 UBC cohort. Black bars, TERT mutated; HG, high-grade; LG, low-grade; White bars, positive cytology.

Table 3. Correlation of somatic TERT promoter mutation with the appearance of pTis stage in the evolution of the disease in a subset of 50 patients with non-tumour stage at the resection

\begin{tabular}{l|c|c|c|}
\hline PTis stage & $\mathbf{n}$ & Mutated TERT & $\boldsymbol{P}_{\text {-value }}$ \\
\hline Yes & 13 & $10(76.9 \%)$ & \\
\hline No & 37 & $13(35.1 \%)$ & 0.0214 \\
\hline $\begin{array}{l}\text { Abbreviation: TERT = telomerase reverse transcriptase. } \\
\text { a P-value corresponds to Fisher's exact test. }\end{array}$
\end{tabular}

presented a TERT mutation (specificity 96.3\%, 26 out of 27). As prostate cancer could have been associated with TERT mutation, we also studied a group of patients with prostate cancer and without known UBC. In this group, specificity of TERT mutations was $87.9 \%$ (29 out of 33 ).

Detection of residual CIS after TUBR. Analysis of follow-up urines from the 348 patients found that in some cases TERT remained positive after TUBR whereas histopathology on the surgical specimen was negative for UBC, which could point to the presence of residual CIS. To test this hypothesis we analysed the association between TERT status and presence of pTis lesions detected during follow-up in patients with 'non-tumour' pathology post-TUBR $(n=50$; Table 3$)$. Among the 13 patients with recurrence of a confirmed CIS within 6 months after initial TUBR, $10(76.9 \%)$ had follow-up urine (1 month post-surgery) that remained positive for TERT mutation, whereas among the 35 who did not have recurrence, $35.1 \%$ remained positive. TERT mutation was significantly associated with 6-month recurrence of pTis $(P=0.0214)$.

Prediction of recurrence in NMIBC by TERT in urine. Patients presenting with NMIBC are known to be at risk of recurrence with more invasive tumours. We therefore evaluated whether TERT in urine could detect such recurrence, by analysing the association of TERT status with RFS in 100 patients with a minimum follow-up of 6 months and initially presenting a NMIBC without pTis (because it is known to increase risk of recurrence). Presence of TERT promoter mutation in urine was strongly associated with recurrence in these NMIBC patients (Figure 2A, $P<0.0001$ ). Results of univariate RFS analysis showed that TERT mutation was associated with a risk of recurrence that increased 5.34-fold in the NMIBC subset (95\% CI 2.11-13.55; $P=0.0004)$. This association 
A

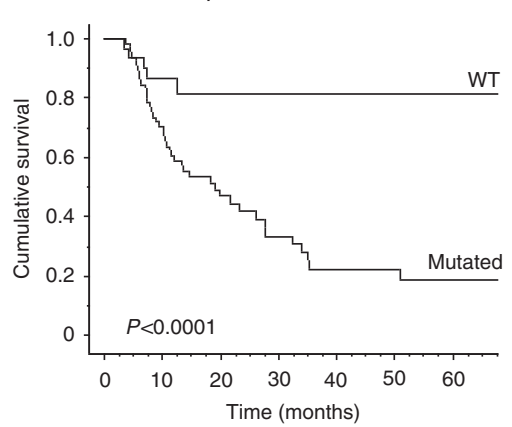

Number of events

$\begin{array}{llrrrrrr}\text { Mutated } & - & 19 & 32 & 37 & 41 & 41 & 42\end{array}$

Number at risk

$\begin{array}{llllllll}\text { Mutated } & 67 & 42 & 21 & 12 & 8 & 7 & 5\end{array}$
B

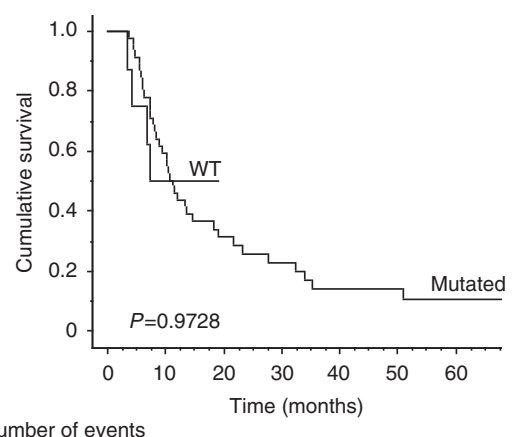

Number of events

$\begin{array}{llrrrrrr}\text { Mutated } & - & 18 & 30 & 33 & 36 & 36 & 37 \\ \text { WT } & - & 4 & 4 & 4 & 4 & 4 & 4\end{array}$

Number at risk

Mutated 45

WT
Positive cystoscopy

4

11
C

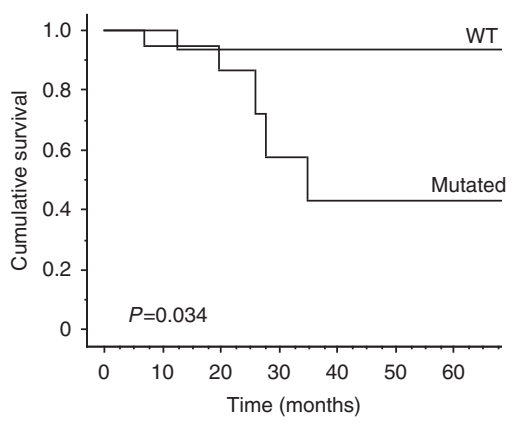

Number of events

$\begin{array}{llllllll}\text { Mutated - } & 1 & 2 & 4 & 5 & 5 & 5 \\ \text { WT } & - & 0 & 1 & 1 & 1 & 1 & 1\end{array}$

Number at risk

Mutated 22

WT

Figure 2. Recurrence-free survival and TERT status. Kaplan-Meier curves for RFS probabilities according to somatic TERT promoter mutation alone (A) or associated with positive cystoscopy (B) and negative cystoscopy (C) in the NMIBC subset $(n=100)$.

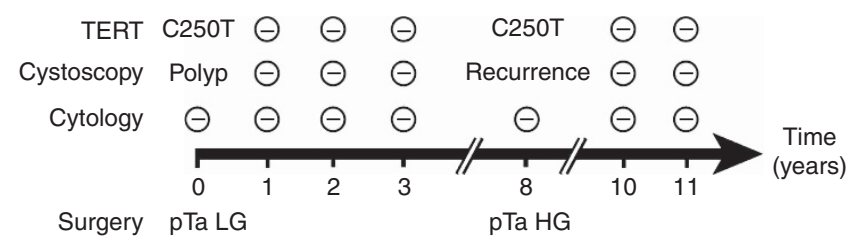

Figure 3. Example of somatic TERT promoter mutation status and patient outcome. HG, high-grade; LG, low-grade; - , negative result.

did not persist in multivariate analysis when associated with cystoscopy in the Cox regression model (HR 1.72, 95\% CI $0.61-$ $4.81 P=0.3015)$. However when patients were stratified on cystoscopy status, TERT mutation positivity was still significantly associated with recurrence (Figure $2 \mathrm{C}, P=0.034$ ) in the negative cystoscopy subset (46 out of 100 patients), despite only a few numbers of events ( 5 out of 6 were TERT mutated). TERT mutation did not provide additional information in terms of RFS in the positive cystoscopy subset $(n=54$; Figure $2 \mathrm{~B}, P=0.9728)$.

Dynamic follow-up of NMIBC patients using TERT. We also observed that presence of TERT mutations in urine was a dynamic marker of recurrence. A frequent scenario is exemplified by the case presented in Figure 3. This patient was initially treated by TUBR for a NMIBC classified as low-grade pTa. He presented a $\mathrm{C} 250 \mathrm{~T}$ mutation that became negative in the follow-up urines. Seven years later, TERT became positive again, associated with cystoscopic signs of recurrence. A tumour classified as high-grade pTa was resected. Since this second surgery (three years follow-up) urines have remained negative for TERT mutation and the patient has not experienced recurrence. Of note, urine cytology remained negative throughout progression of the disease, including initial tumour and recurrence.

\section{DISCUSSION}

Results of this large cohort study demonstrate that detecting TERT promoter mutations in urine is a non-invasive and sensitive way to detect UBC lesions, even of low-grade, where cytology is not sensitive enough. TERT may help to detect recurrence earlier and to better adapt follow-up frequency and treatment. We further showed that TERT remained positive after TUBR was significantly associated with residual CIS, which is difficult to detect by standard cystoscopy. This could explain why TERT remained a predictor of recurrence even in the negative cystoscopy group. Therefore TERT testing could help to better identify the group of patients for whom to consider hexaminolevulinate fluorescence cystoscopy.

However, around $20 \%$ of patients did not show positive TERT in urine after initial TUBR and remained negative during followup. Because TERT is known to be reactivated by mechanisms other than mutations of its promoter, it may be of interest to study TERT expression and activity in these non-mutated patients (Hurst et al, 2014). Importantly we also found that detection of TERT mutation remained highly specific in inflammatory or infectious urines where previously described urinary biomarkers are known to give false-positive results (Raitanen et al, 2001; Chou et al, 2015). This is an important issue since this type of urine is frequent in non-UBC patients. Furthermore, TERT could also help clinicians to distinguish recurrence from inflammatory scar in case of suspicious cystoscopy.

The study does have some limitations. The main one being the single-centre design that could introduce some positive bias in analysing the performance of this marker.

A prospective study, investigating combination of TERT with FGFR3 and OTX1 as diagnostic urinary markers during follow-up of patients with primary NMIBC, recently confirmed the interest of this panel in patients with negative cystoscopy (Beukers et al, 2017). It would be important to define the negative predictive value of TERT mutation as a single marker in case of suspicious cystoscopy (inflammatory lesions, scar post BCG therapy, etc.), and its positive predictive value in case of negative cystoscopy and cytology.

\section{CONCLUSIONS}

Detection of TERT promoter mutations in urine is a reliable noninvasive prognostic marker for recurrence in UBC, especially in NMIBC where cytology does have some limitations.

\section{ACKNOWLEDGEMENTS}

This study was supported by the French Ministry of Health (PHRC National 2006). We would to thank Florence Morin for her technical support, Dr Pierre Sujobert for his constructive comments on this manuscript and Philip Robinson (Hospices Civils de Lyon) for editorial help. 


\section{CONFLICT OF INTEREST}

All named authors declare that they have no competing interest. They have agreed to the submission and have participated in the study to a sufficient extent to be named as authors.

\section{REFERENCES}

Allory Y, Beukers W, Sagrera A, Flández M, Marqués M, Márquez M, van der Keur KA, Dyrskjot L, Lurkin I, Vermeij M, Carrato A, Lloreta J, Lorente JA, Carrillo-de Santa Pau E, Masius RG, Kogevinas M, Steyerberg EW, van Tilborg AAG, Abas C, Orntoft TF, Zuiverloon TCM, Malats N, Zwarthoff EC, Real FX (2014) Telomerase reverse transcriptase promoter mutations in bladder cancer: high frequency across stages, detection in urine, and lack of association with outcome. Eur Urol 65: 360-366.

Bassi P, De Marco V, De Lisa A, Mancini M, Pinto F, Bertoloni R, Longo F (2005) Non-invasive diagnostic tests for bladder cancer: a review of the literature. Urol Int 75: 193-200.

Beukers W, van der Keur KA, Kandimalla R, Vergouwe Y, Steyerberg EW, Boormans JL, Jensen JB, Lorente JA, Real FX, Segersten U, Orntoft TF, Malats N, Malmström P-U, Dyrskjot L, Zwarthoff EC (2017) FGFR3, TERT and OTX1 as a urinary biomarker combination for surveillance of patients with bladder cancer in a large prospective multicenter study. J Urol 197: 1410-1418.

Chou R, Gore JL, Buckley D, Fu R, Gustafson K, Griffin JC, Grusing S, Selph S (2015) Urinary biomarkers for diagnosis of bladder cancer: a systematic review and meta-analysis. Ann Intern Med 163: 922-931.

Collin-Chavagnac D, Marçais C, Billon S, Descotes F, Piaton E, Decaussin M, Rodriguez-Lafrasse C, Ruffion A (2010) Quantitative loss of heterozygosity analysis for urothelial carcinoma detection and prognosis. Urology 76: 515.e1-e7.

Descotes F, Dessen P, Bringuier PP, Decaussin M, Martin PM, Adams M, Villers A, Lechevallier E, Rebillard X, Rodriguez-Lafrasse C, Devonec M, Paparel P, Perrin P, Lazar V, Ruffion A (2014) Microarray gene expression profiling and analysis of bladder cancer supports the sub-classification of T1 tumours into T1a and T1b stages. BJU Int 113: 333-342.

Fontaniere B, Ranchere-Vince D, Landry JL, Colombel M, Chopin D, Gattegno B (2001) [Quality criteria in urinary cytology for tumor diagnosis]. Prog Urol 11: 867-875.

Geavlete B, Jecu M, Multescu R, Geavlete P (2012) Narrow-band imaging cystoscopy in non-muscle-invasive bladder cancer: a prospective comparison to the standard approach. Ther Adv Urol 4: 211-217.

Grossman HB, Gomella L, Fradet Y, Morales A, Presti J, Ritenour C, Nseyo U, Droller MJ, PC B302/01 Study Group (2007) A phase III, multicenter comparison of hexaminolevulinate fluorescence cystoscopy and white light cystoscopy for the detection of superficial papillary lesions in patients with bladder cancer. J Urol 178: 62-67.

Hanahan D, Weinberg RA (2011) Hallmarks of cancer: the next generation. Cell 144: 646-674.

Horn S, Figl A, Rachakonda PS, Fischer C, Sucker A, Gast A, Kadel S, Moll I, Nagore E, Hemminki K, Schadendorf D, Kumar R (2013) TERT promoter mutations in familial and sporadic melanoma. Science 339: 959-961.

Huang FW, Hodis E, Xu MJ, Kryukov GV, Chin L, Garraway LA (2013) Highly recurrent TERT promoter mutations in human melanoma. Science 339: 957-959.
Hurst CD, Platt FM, Knowles MA (2014) Comprehensive mutation analysis of the TERT promoter in bladder cancer and detection of mutations in voided urine. Eur Urol 65: 367-369.

Killela PJ, Reitman ZJ, Jiao Y, Bettegowda C, Agrawal N, Diaz LA, Friedman AH, Friedman H, Gallia GL, Giovanella BC, Grollman AP, He T-C, He Y, Hruban RH, Jallo GI, Mandahl N, Meeker AK, Mertens F, Netto GJ, Rasheed BA, Riggins GJ, Rosenquist TA, Schiffman M, Shih I-M, Theodorescu D, Torbenson MS, Velculescu VE, Wang T-L, Wentzensen N, Wood LD, Zhang M, McLendon RE, Bigner DD, Kinzler KW, Vogelstein B, Papadopoulos N, Yan H (2013) TERT promoter mutations occur frequently in gliomas and a subset of tumors derived from cells with low rates of self-renewal. Proc Natl Acad Sci USA 110: 6021-6026.

Koss LG, Deitch D, Ramanathan R, Sherman AB (1985) Diagnostic value of cytology of voided urine. Acta Cytol 29: 810-816.

Layfield LJ, Elsheikh TM, Fili A, Nayar R, Shidham V, Papanicolaou Society of Cytopathology (2004) Review of the state of the art and recommendations of the Papanicolaou Society of Cytopathology for urinary cytology procedures and reporting: the Papanicolaou Society of Cytopathology Practice Guidelines Task Force. Diagn Cytopathol 30: 24-30.

Miremami J, Kyprianou N (2014) The promise of novel molecular markers in bladder cancer. Int J Mol Sci 15: 23897-23908.

Piaton E, Decaussin-Petrucci M, Mege-Lechevallier F, Advenier A-S, Devonec M, Ruffion A (2014) Diagnostic terminology for urinary cytology reports including the new subcategories 'atypical urothelial cells of undetermined significance' (AUC-US) and 'cannot exclude high grade' (AUC-H). Cytopathology 25: 27-38.

Piaton E, Hutin K, Faÿnel J, Ranchin M-C, Cottier M (2004) Cost efficiency analysis of modern cytocentrifugation methods versus liquid based (Cytyc Thinprep) processing of urinary samples. J Clin Pathol 57: 1208-1212.

Raitanen M-P, FinnBladder Group (2008) The role of BTA stat Test in follow-up of patients with bladder cancer: results from FinnBladder studies. World J Urol 26: 45-50.

Raitanen MP, Kaasinen E, Lukkarinen O, Kauppinen R, Viitanen J, Liukkonen T, Tammela TL, Finnbladder Group (2001) Analysis of false-positive BTA STAT test results in patients followed up for bladder cancer. Urology 57: 680-684.

Rosser CJ, Chang M, Dai Y, Ross S, Mengual L, Alcaraz A, Goodison S (2014) Urinary protein biomarker panel for the detection of recurrent bladder cancer. Cancer Epidemiol Biomarkers Prev 23: 1340-1345.

Sauter G (2004) In: Pathology and Genetics of Tumours of the Urinary System and Male Genital Organs. Eble JN, Sauter G, Epstein JI, Sesterhenn IA (eds). IARC Press: Lyon, France.

Schmidt JC, Cech TR (2015) Human telomerase: biogenesis, trafficking, recruitment, and activation. Genes Dev 29: 1095-1105.

Ward DG, Baxter L, Gordon NS, Ott S, Savage RS, Beggs AD, James JD, Lickiss J, Green S, Wallis Y, Wei W, James ND, Zeegers MP, Cheng KK, Mathews GM, Patel P, Griffiths M, Bryan RT (2016) Multiplex PCR and next generation sequencing for the non-invasive detection of bladder cancer. PloS One 11: e0149756.

Wu S, Huang P, Li C, Huang Y, Li X, Wang Y, Chen C, Lv Z, Tang A, Sun X, Lu J, Li W, Zhou J, Gui Y, Zhou F, Wang D, Cai Z (2014) Telomerase reverse transcriptase gene promoter mutations help discern the origin of urogenital tumors: a genomic and molecular study. Eur Urol 65: 274-277.

This work is published under the standard license to publish agreement. After 12 months the work will become freely available and the license terms will switch to a Creative Commons AttributionNonCommercial-Share Alike 4.0 Unported License. 